\title{
Assembly Line Balancing Optimization Based on Simulation
}

\author{
Xiaobing Pei ${ }^{a}$, Hongyang Cha ${ }^{b}$ \\ School of Management, Tianjin University of Technology, Tianjin, 300384, China \\ acims1995@126.com, b904178210@qq.com
}

Keywords: assembly; simulation; improvement; balance.

\begin{abstract}
Simulation is often used to model the production process in order to achieve understanding and improve their purpose, to make the text in order to develop the visualization process automation and use ergonomic principles and process layout principles to improve before the aid Em-plant simulation software to improve results after modeling analysis to confirm the feasibility of optimization and more conducive to the production managers to understand the current situation.
\end{abstract}

\section{Introduction}

Today, market competition, enterprises should improve the competitiveness of production costs must be reduced to achieve efficient production of how to improve the efficiency of the assembly line of production to minimize the processing time synchronization performed by the manufacturer's assembly line balancing emphasis on design is one means of achieving this goal. SMEs in the assembly line, the prevalence of work arrangements is unreasonable, in the article too long production cycle, staff waiting more time and a series of problems. So a successful manufacturing company which is the implementation of that concept that is agile production costs are minimized and reduce variation.

Assembly line workstations is included in contiguous and continuous operation of production systems. Part is completed before moving onto the next step until. They are widely used in many enterprises because they effectively produce large amounts of standardized products.

\section{Progress of Simulation}

\subsection{Situation Study Abroad}

Currently on the simulation study abroad have to optimize the production line model Faisal Aqlan implement dashboard in order to configure the production environment; Nooshin Rahmani simulation-based optimization using the best technology to design automobile plant retouch line by solving optimization model proposed facilities and workstations quantity; Rami Musa optimization Simulation - Optimization of the upper assembly on the basis of changes reduce initiative; Öncü Hazir under conditions of uncertainty in the pipeline proposed a new model based on the decomposition of the exact algorithm development and thus design an assembly line production rate will be more reliable;

\subsection{Domestic Em-plant Study}

About em-plant studies have Yunmin Ma domestic use UML modeling workshop operating system analysis and mapping implemented in simulation software em-plant; the results of the simulation software Chenshu Hong em-plant modeling and analysis product line pre-planning can play to good supporting role; Chen was frequently using SLP method optimization workshop facility layout; Yu Jun, use em-plant machine tool production line pull simulation thereby reducing inventory; Yang Dongliang by em-plant in order to beat the problem of automobile production line is variable simulation to improve production efficiency; Zhu Qiong draw a compressor factory assembly plant utilization by each station em-plant simulation software can clearly understand the current situation. 


\section{A Domestic Enterprise Status}

\subsection{Improve the State before the Assembly Line}

A business is one of the large-scale production of electric tricycle professional enterprise, the main production line of its assembly plant effective daily working time is eight hours using a batch production assembly line at the same time to spend electric cars, for example its assembly process coupled with each the time required for the station.

Table 1 Prior to assembly line process improvement

\begin{tabular}{|c|c|c|}
\hline 1 & Smashing bowl & 10 \\
\hline 2 & Frame flip & 43 \\
\hline 3 & Rear axle & 20 \\
\hline 4 & Lug & 31 \\
\hline 5 & Fork & 32 \\
\hline 6 & Handlebar & 44 \\
\hline 7 & Shun line & 55 \\
\hline 8 & Single hook, rear & 45 \\
\hline 9 & Tightening & 37 \\
\hline 10 & Bucket seat & 45 \\
\hline 11 & Hydraulic pull arm, & 20 \\
\hline 12 & Loading carriage & 39 \\
\hline 13 & Backrest cushion & 30 \\
\hline 14 & Applique & 52 \\
\hline 15 & Get off & 15 \\
\hline 16 & Windshield & 31 \\
\hline 17 & Trademark & 43 \\
\hline 19 & Vehicle inspection & 40 \\
\hline & Package & 50 \\
\hline & Total & 682 \\
\hline
\end{tabular}

The balance was drawn $\varepsilon=\frac{\sum t_{i}}{s \times R} \times 100 \%=\frac{682}{55 \times 19} \times 100 \%=65 \%$

Through on-site observation of enterprises currently exists, in articles online too, blockage situation is quite serious, affecting the previous station has been unable to successfully complete the process is transferred to the next station. Staff are more complex work processes, some workers exist action stations operating waste, as well as some confusion station layout, decoration materials messy cause prolonged working hours and appear waiting phenomenon.

\section{Analysis and Improvement}

\subsection{Analysis of differential Pre-action Report}

With Video Analysis APP operates on differential pre-analysis, due to the finished car farther away from the table, all kinds of raw materials caused by ineffective distribution of scattered car walking, after improvement can reduce the total time from the differential pre-88s to the $81 \mathrm{~s}$ as table 2 , each differential lower $7 \mathrm{~s}$.

By the above method, respectively the seat backrest, left decal, smashing bowl, flip frame, rear axle installation, and adjustment lever, hanging along the line to improve and improve the overall process of the ear. 


\section{2 improve and implement}

Through a series of continuous flow assembly line problems found improvements such as smashing bowl workers decreased from two to one, to replace the frame at the installed flip coil and shock absorption leather work; differential pre personnel and smashed work bowl synchronous operations, also responsible for the installed differential bow shaped plate carried on the assembly line, eliminating the need for the two original handling of the rear axle; the first sequence on the assembly line employees that is responsible for installing lug bolts on both sides and tightening; pre relay step to shun harness employees, their original relay station fastened to the sixth controller mounted charging cradle; original fastening the controller to install the charging dock workers to the 7th station pressure trucking, fastening relay, seat tube; get off at the drop of a fitting, take the stand staff change to the 7 th station put the seat tube, tie wire harnesses, electrical inspection, fitting seat tube. Before loading the wind, nail nameplate; omit this step at the original electrical inspection, the pressure trough, the two fastening seat tube; pull the arm mounted at one end, moving the car and loaded the car step merger process, eliminating the need for a person on-line; one person in charge of pre-installed windshield, nail plate, another person in charge of loading the wind, put the accessories, eliminating the original nail nameplate of a person; in charge of inspection turner off, eliminating the need for a special one off original work. The improved balance rate

Through a series of continuous flow assembly line problems found improvements such as smashing bowl workers decreased from two to one, to replace the frame at the installed flip coil and shock absorption leather work; differential pre personnel and smashed work bowl synchronous operations, also responsible for the installed differential bow shaped plate carried on the assembly line, eliminating the need for the two original handling of the rear axle; the first sequence on the assembly line employees that is responsible for installing lug bolts on both sides and tightening; pre relay step to shun harness employees, their original relay station fastened to the sixth controller mounted charging cradle; original fastening the controller to install the charging dock workers to the 7th station pressure trucking, fastening relay, seat tube; get off at the drop of a fitting, take the stand staff change to the 7 th station put the seat tube, tie wire harnesses, electrical inspection, fitting seat tube. Before loading the wind, nail nameplate; omit this step at the original electrical inspection, the pressure trough, the two fastening seat tube; pull the arm mounted at one end, moving the car and loaded the car step merger process, eliminating the need for a person on-line; one person in charge of pre-installed windshield, nail plate, another person in charge of loading the wind, put the accessories, eliminating the original nail nameplate of a person; in charge of inspection turner off, eliminating the need for a special one off original work. The improved balance rate

$$
\varepsilon=\frac{\sum t_{i}}{s \times R} \times 100 \%=\frac{646}{52 \times 15} \times 100 \%=82.8 \%
$$

\section{Em-plant Simulation results of the Statistical Analysis}

By observing a day ( 8 hours) after the results of a simulation run is seen to improve the overall throughput of the electric car assembled by the 512 to improve increased to 542 before the increase of 30 , for the simulation output results compare

Table 2 Comparison improve production capacity before and after

\begin{tabular}{|c|c|c|}
\hline & before & after \\
\hline Yield (vehicles / day) & 512 & 542 \\
\hline Per capita productivity (veh / day * person) & 12.19 & 15.94 \\
\hline Balance rate & $65 \%$ & $82.8 \%$ \\
\hline
\end{tabular}

That increase production, reduce line staff, increase worker efficiency, cost savings, changed the original imbalance, more conducive to the development of the plant according to the simulation output. 


\section{Summary and Future Research}

Simulation optimization method, although able to reflect improved outcomes but only to show, it found the problem, rather than have to change the production systems to facilitate more detailed internal operations through software, it is through artificial means causes low productivity to sequentially addressed. Of course, the movement of materials to reduce the distance, frequency, and the number of personnel required for the movement of materials should also be gradually reduced an important part also needs to be improved in the future.

Our goal is to reduce inspection costs and minimized assembly costs, changes in the future, we are also part by reducing the overall inspection program matching allows us to produce the final assembly of the lowest failure rates.

\section{Reference}

[1]Andrzej Marek Lasota.ANALYSIS OF PACKERS' WORKLOAD ON THE PACKING LINE -A CASE STUDY.Scientific[J] Journal of Logistics,2014,10 (4): 383-392

[2]FaisalAqlan.An integrated simulation-optimization study for consolidating production lines in a configure-to-orderproductionenvironment[J].Int. J.ProductionEconomics,2014,148:51-61

[3]Öncü Hazır.Assembly line balancing under uncertainty: Robust optimization models and exact solution method[J].Computers \& Industrial Engineering,2013,65:261-267

[4]Sang Hyeok Han.Automated post-simulation visualization of modular building production assembly line[J].Automation in Construction,2012,21:229-236

[5]Nooshin Rahmani.Designing the retouch line in an automobile factory using a simulation-based optimization technique; a real case study[J].Procedia - Social and Behavioral Sciences , 2012,62: 995 $-1000$ 